\title{
Electron microscopic studies in desquamative interstitial pneumonia associated with asbestos
}

\author{
B. COR RIN and A. B. PRICE \\ Departments of Pathology, St. Thomas's Hospital Medical School, London, S.E.1 and \\ St. Mary's Hospital, Portsmouth
}

\begin{abstract}
A case of desquamative interstitial pneumonia (DIP) has been studied by electron microscopy in order to determine the nature of the alveolar cells. Those lining the alveolar walls proved to be granular pneumocytes (type II alveolar epithelial cells) while cells free in the lumen were alveolar macrophages. The brief literature describing the electron microscopic findings in DIP is reviewed. All workers agree that the lining cells are granular pneumocytes and most report a mixed free cell population with the emphasis shifting from desquamated epithelial cells to macrophages. In the present case asbestos bodies were also found in the lung, suggesting that DIP is not a specific disease entity.
\end{abstract}

Desquamative interstitial pneumonia (DIP) was first described by Liebow, Steer, and Billingsley in 1965. It was distinguished histologically from other forms of interstitial pneumonia by an abundance of cells filling and lining the alveolar spaces and by relatively little thickening of the alveolar walls, while clinically the disease was notable for a good response to steroids. Scadding and Hinson (1967) challenged the view that DIP represented a specific entity and regarded its features as forming merely one end of a spectrum of changes seen in diffuse fibrosing alveolitis; such cases they term the desquamative type of fibrosing alveolitis. Until the causation and pathogenesis of interstitial pneumonia are better understood this question will remain arguable. Greater agreement has been reached on the beneficial effects of steroids, and whatever terminology is favoured, it is therefore important to recognize the pathological changes so that proper therapy may be instituted. For this reason, the status of DIP is now widely accepted in clinical practice.

Another debatable question concerns the nature of the alveolar cells, and to those workers interested in the cytological composition of the lung and the dynamics of its respective cell populations this matter is of considerable importance. The term 'desquamative' is used to imply derivation of the free cells from the alveolar lining cells, but it is recognized that light microscopy is incapable of accurate cytological characterization (Liebow et al., 1965; Scadding and Hinson, 1967). Preliminary ultrastructural studies led the original workers to believe that the free cells were epithelial in origin, but it was admitted that the electron microscopic evidence was fragmentary and the fine structural appearances were neither described nor illustrated. Support for the free cells being desquamated type II alveolar epithelial cells (granular pneumocytes) came from a case studied by Goff, McNary, and Gaensler (1967), but unfortunately their illustration of a free granular cell appears to show the dense bodies of an alveolar macrophage rather than the lamellar inclusions characteristic of a granular pneumocyte. The ultrastructural distinction between these cell types was clearly recognized by Shortland, Darke, and Crane (1969) and in their case of DIP both granular pneumocytes and macrophages were found free in the alveoli, with the former predominating. Brewer, Heath, and Asquith (1969) also drew a clear distinction between granular and phagocytic pneumocytes, and in their case both cell types were again found free in the lumen, but macrophages predominated. Very similar findings were reported in two cases of DIP carefully studied by Leroy (1969). The only other electron microscopic study of DIP of which we have knowledge is that of Farr, Harley, and Hennigar (1970). These workers reported that macrophages make up $90 \%$ of the intra-alveolar cell population.

It is clear, therefore, that the few cases of DIP studied with the electron microscope provide contradictory evidence on the nature of the free alveolar cells. We now report a further case of DIP and pay particular attention to the electron micro- 
scopic characterization of the lining and free alveolar cells.

\section{CASE REPORT}

A 48-year-old man presented with a six-month history of gradually increasing dyspnoea and joint pain. He gave no history of productive cough, chest pain, allergy or contact with domestic pets. Although employed in a dockyard he had no known direct contact with asbestos. He had smoked 10 cigarettes per day until one year previously. Eight years earlier he had undergone gastrectomy for peptic ulceration but had otherwise been a fit man.

On examination he had diminished air entry at both lung bases. Finger clubbing was noted and there was swelling of the elbow and metacarpophalangeal joints.

Laboratory investigations included the following: Hb $9.4 \mathrm{~g} / 100 \mathrm{ml}$; ESR $34 \mathrm{~mm} / \mathrm{hr}$ (Westergren); fluorescent antibody to antinuclear factor positive; Rose Waaler test negative; arterial blood gases- $\mathrm{pH}$ $7 \cdot 38, \mathrm{PCO}_{2} 42 \mathrm{mmHg}, \mathrm{Po}_{2} 78 \mathrm{mmHg}$, standard bicarbonate $24 \mathrm{mEq} / 1$., base excess nil.

Respiratory function:

Forced expiratory volume in $1 \mathrm{sec}$. (ml.)

(Predicted normal value 2,950)

Forced vital capacity (ml)

(Predicted normal value 3,680)

$$
\text { Ratio: } \frac{\text { FEV }_{1} \times 100}{\text { FVC }} \quad 84 \%
$$

(Predicted normal value $80 \%$ )
A chest radiograph showed fine nodular shadowing at both lower zones and to a lesser degree in the midzones. There was no radiographic evidence of arthritis or pulmonary neoplasm. A lung biopsy, described in detail below, was reported as showing desquamative interstitial pneumonia. The anaemia responded to iron, his symptoms improved, and he was able to return to work. It was therefore decided to withhold steroids. One year later the patient was clinically well. The most recent chest radiograph showed no alteration in the lung picture.

\section{PATHOLOGICAL FINDINGS}

The excised piece of lung tissue measured $3 \times 2 \times 1$ $\mathrm{cm}$. It was fixed in $10 \%$ formalin and half the specimen was processed for light microscopy. Paraffin sections stained with haematoxylin and eosin showed filling of almost all the alveoli and bronchioles by large eosinophilic cells of variable shape, which occasionally assumed a multinucleate giant cell form (Figs 1 and 2). Some of the intraalveolar cells showed mitotic activity and many contained a brown pigment which gave a strongly positive periodic acid-Schiff reaction. As well as these intraluminal cells, many alveoli were lined by prominent cells which appeared to form a cuboidal epithelium (Fig. 2). The distinction between the free and mural cells was often difficult,

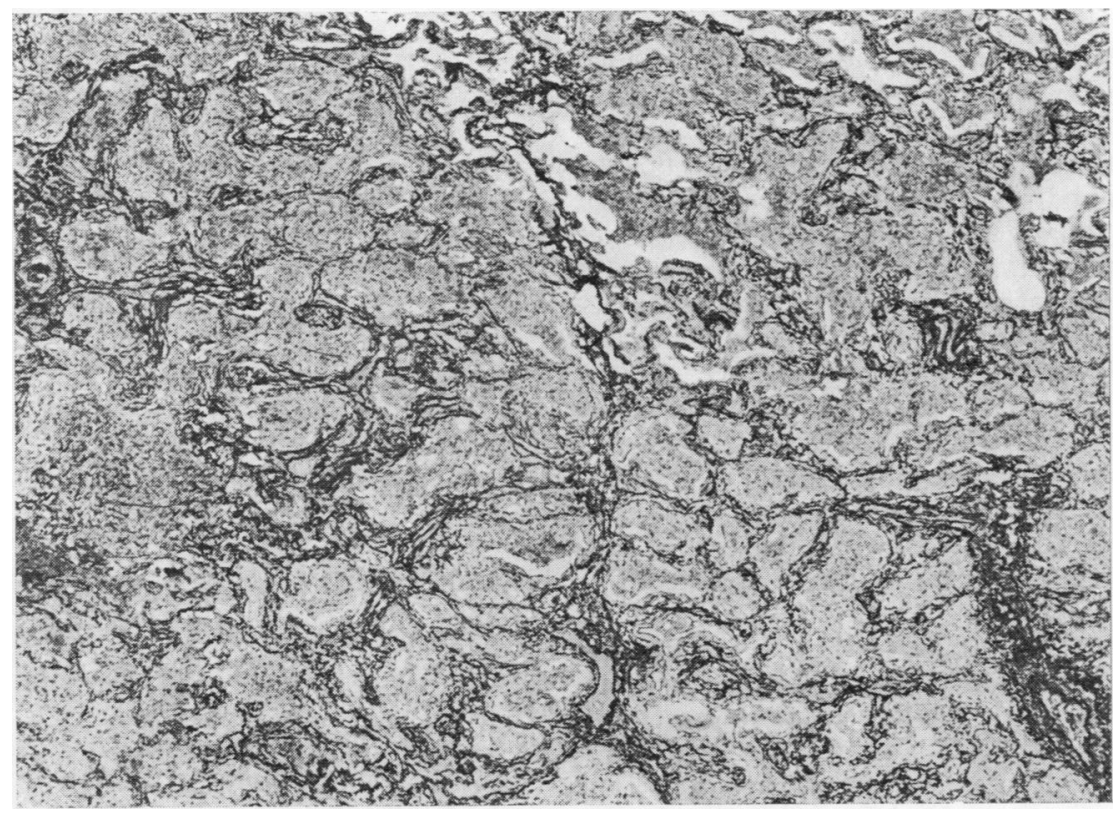

FIG. 1. There is mild thickening of the alveolar walls while the air spaces are largely filled by a cellular exudate. Gordon and Sweet's reticulin stain $\times 48$. 


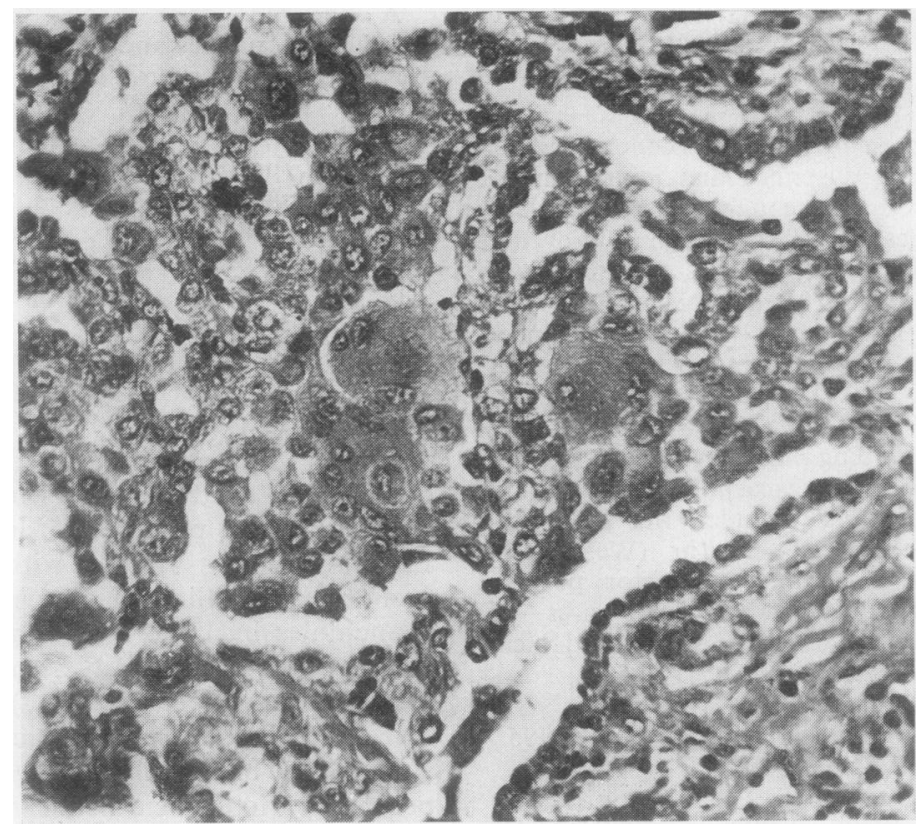

FIG. 2. Free cells, some of them multinucleate, fill the alveolar lumen. Cuboidal cells line the alveolar walls, which also show fibrous thickening. Haematoxylin and eosin $\times 290$.

at least at the light microscopic level. The alveolar walls also showed modest interstitial thickening by histiocytic, lymphocytic, and plasma cell infiltration. Prominent focal collections of lymphocytes were also found widely scattered throughout the lung tissue. Stains for reticulin and elastin showed slight interstitial fibrosis but no elastosis (Fig. 1). All these features are characteristic of DIP. Discrepancies, however, were found on staining for iron. The brown pigment in the free cells is characteristically PAS-positive and Perls-negative but in the present case both these reactions were strongly positive. Furthermore, the Perls' reaction enabled us to identify scanty ferruginous bodies, probably representing asbestos (Fig. 3). A diagnosis was therefore made of DIP associated with asbestos inhalation.

The reserve tissue was processed for electron microscopy after having been stored in $10 \%$ commercial formalin for 19 days. Small pieces were post-fixed in osmic acid and embedded in Epon, and thin sections, stained with uranyl acetate and lead citrate, were examined in a Siemens electron microscope. Ultrastructural detail was quite adequate despite the prolonged use of commercial

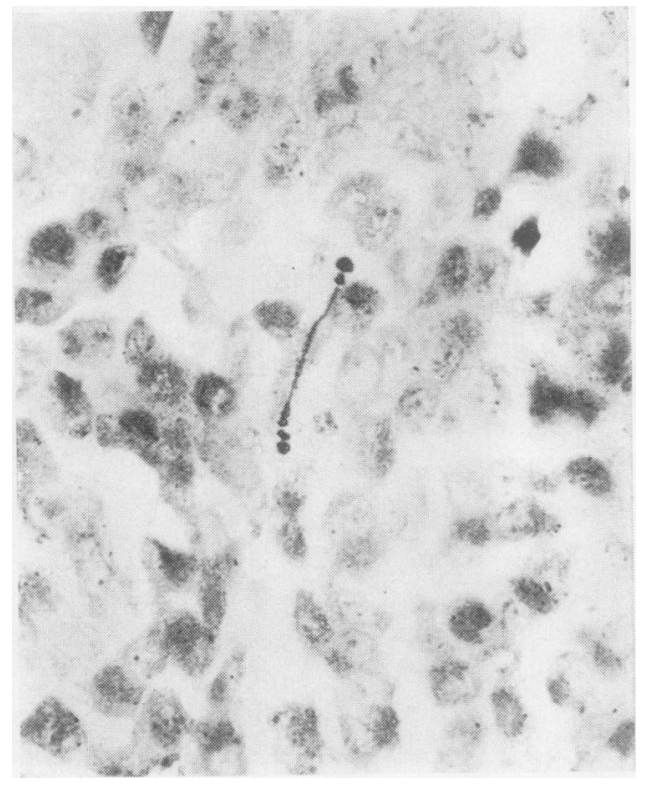

FIG. 3. A ferruginous body in the lung, probably representing asbestos. Perls' stain $\times 480$. 


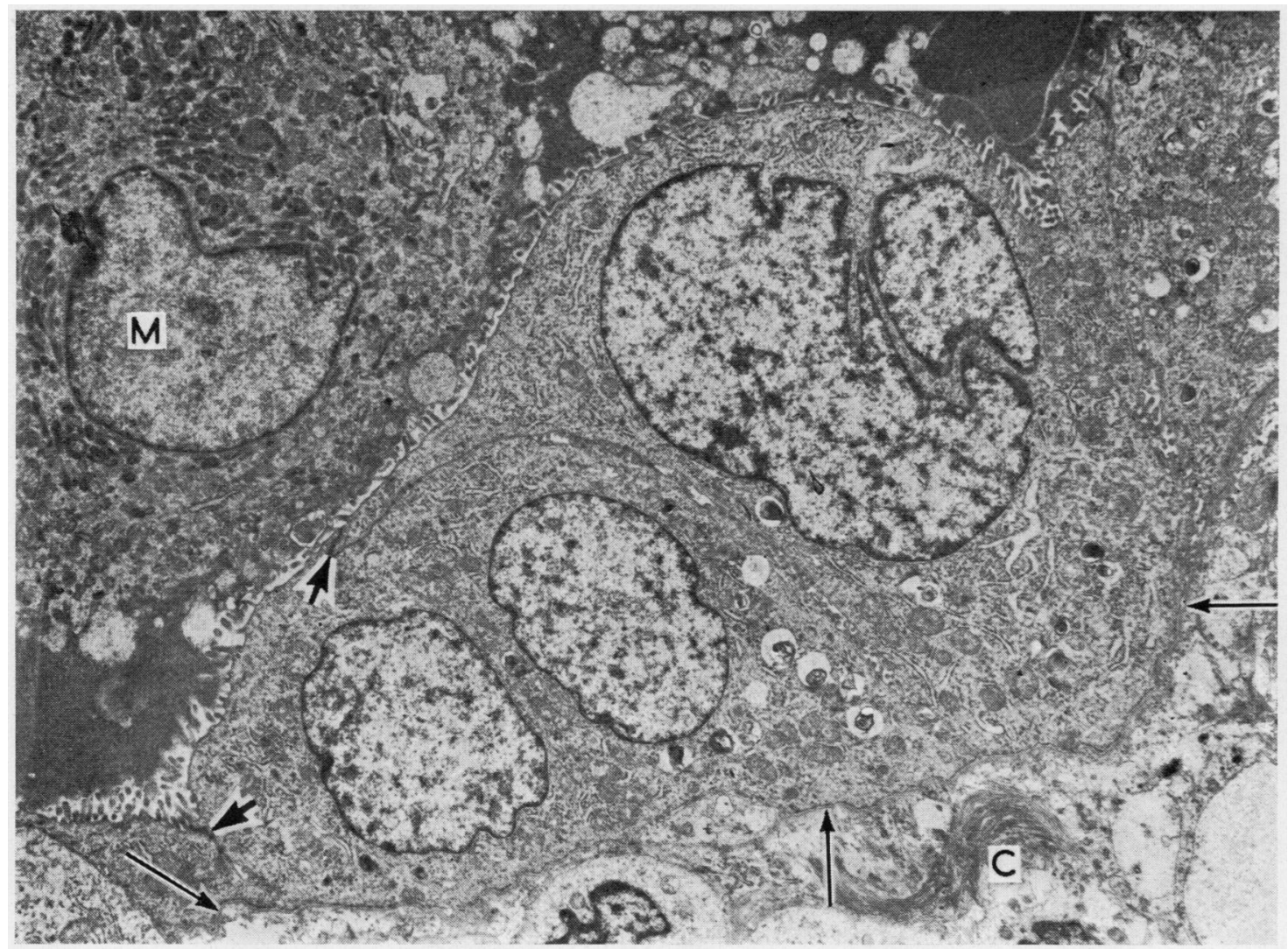

FIG. 4. Part of an alveolar wall lined by a row of granular pneumocytes. These adhere to a basement membrane (arrows) and have intercellular junctions (arrowheads). Their free surfaces are covered by microvilli and their cytoplasm contains scanty small osmiophilic lamellar bodies. A separate cell $(M)$ in the alveolar lumen contains many cytoplasmic dense bodies. Collagen bundles $(C)$ are seen beneath the basement membrane. Electron micrograph: lead and uranium stain EM.L. and $U . \times 3,725$.

formalin; we have previously found that immediate fixation in commercial formalin is less damaging to ultrastructural detail than even quite short delays in fixation (6 hours) or processing to paraffin, both of which seriously disturb cellular fine structure.

Electron microscopy confirmed that the alveoli had a cuboidal epithelium (Fig. 4). The epithelial cells were attached to each other laterally by tight junctions, and on their deeper aspect they adhered to a basement membrane. Their free surface was covered by microvilli, while osmiophilic lamellar inclusions in the cytoplasm varied in number from scanty to numerous. A rich rough-surfaced endoplasmic reticulum, moderate numbers of mitochondria, and small numbers of multivesicular bodies were also present. These cells clearly belonged to the class of alveolar epithelial cell known as the type II or granular pneumocyte (Sorokin, 1966; Meyrick and Reid, 1970). The flattened type I or squamous pneumocytes which normally cover most of the alveolar surface had therefore transformed or given way to type II pneumocytes, which were greatly increased in number. Occasionally this otherwise simple granular cell epithelium was found to be stratified. Where this occurred the innermost cells had lost direct contact with the basement membrane and protruded far into the alveolar lumen. This suggested epithelial desquamation, but indirect contact with the basement membrane was nevertheless maintained in these sites through intact intercellular junctions with deeper cells (Fig. 5).

Necessary to the concept of a cell being free in the lumen is lack of contact with the basement 


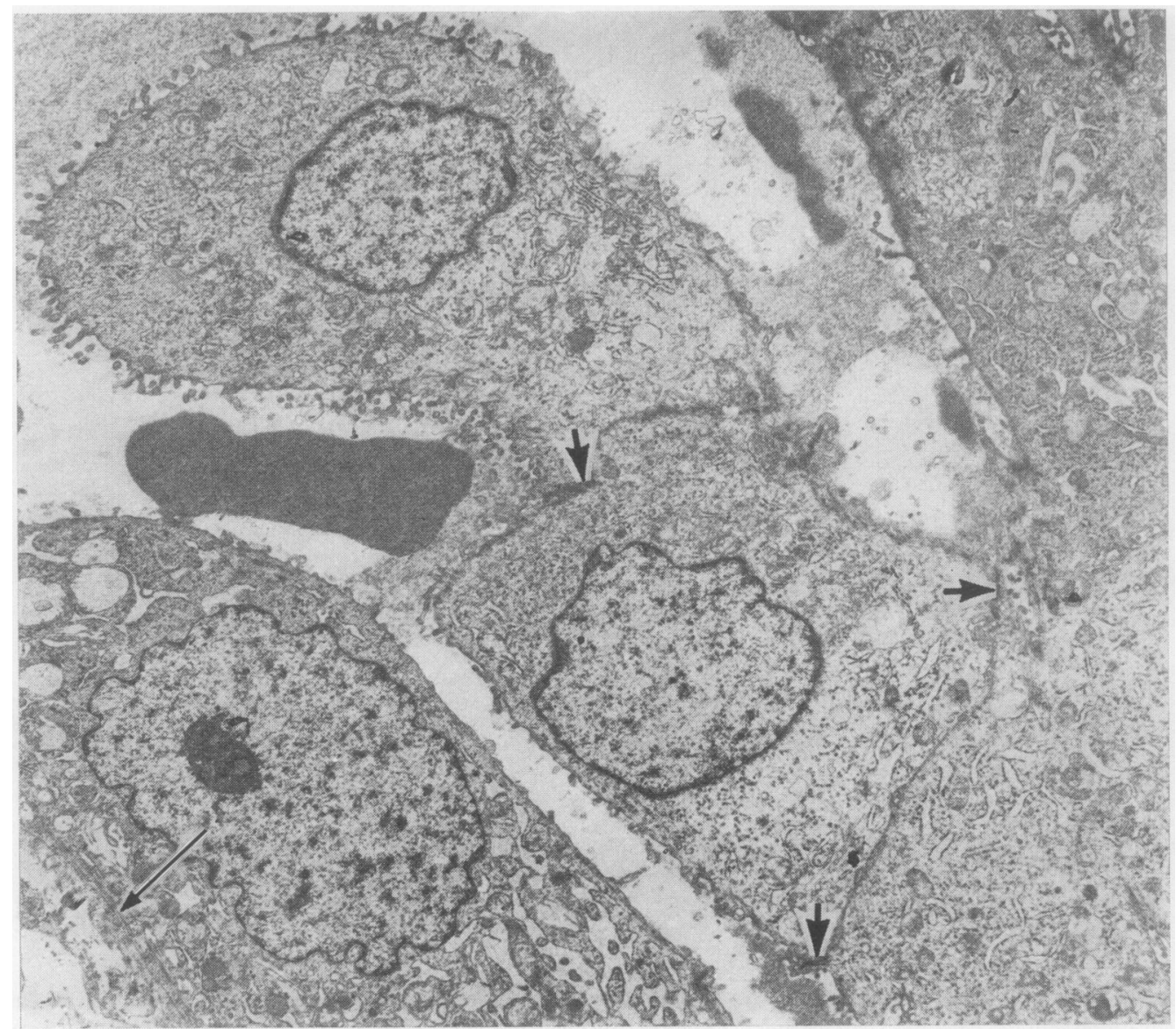

FIG. 5. Granular pneumocytes, only one of which shows attachment to the basement membrane (arrow). Some protrude far into the alveolar lumen but retain an indirect contact with the basement membrane by virtue of their intercellular junctions (arrowheads). They are therefore not free alveolar cells although tangential sectioning could easily give this impression. EM.L. and U. $\times 4,100$.

membrane either directly, or indirectly through intercellular junctions. By these criteria numerous intra-alveolar cells were truly free of the wall and were all of a type quite different from those described above. The free cells were often in close contact with each other but nevertheless were devoid of intercellular junctions. The surfaces of the free cells had no microvilli but were irregular and formed complex folds which interdigitated between one cell and another (Figs 6 and 7). A prominent feature of the free cells was the presence of many membrane-bound dense bodies of varying shape and size (Figs $4,6,7$, and 8 ). The free cells had no lamellar inclusions but possessed a plentiful rough-surfaced endoplasmic reticulum. These features all correspond to those of alveolar macrophages (Karrer, 1958; 1960; Meyrick and 옥 Reid, 1970).

Other features of note include interstitial

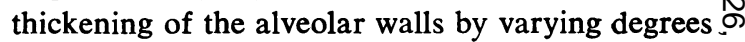
of fibrosis and histiocytic plasma cell and mast cell $N$ infiltration. Leroy (1969) noted interstitial cells $\underset{\mathrm{C}}{\mathrm{N}}$ penetrating the alveolar epithelium to reach the $\sigma$ lumen. We have not observed this phenomenon in DIP but have recorded it in other conditions marked by alveolar macrophage accumulation $\stackrel{\mathcal{\Phi}}{\rightarrow}$ (Vijeyaratnam and Corrin, 1971). No asbestos 0 bodies were found on electron microscopy. Other 0 negative findings, possibly relevant to the aetiology $\overrightarrow{\mathbb{D}}$ of DIP, include a lack of change in the basement $\overrightarrow{\mathbb{D}}$ membranes, absence of any electron-dense deposits $\frac{\varrho}{\sigma}$ suggestive of immune material, and no recogniz- 


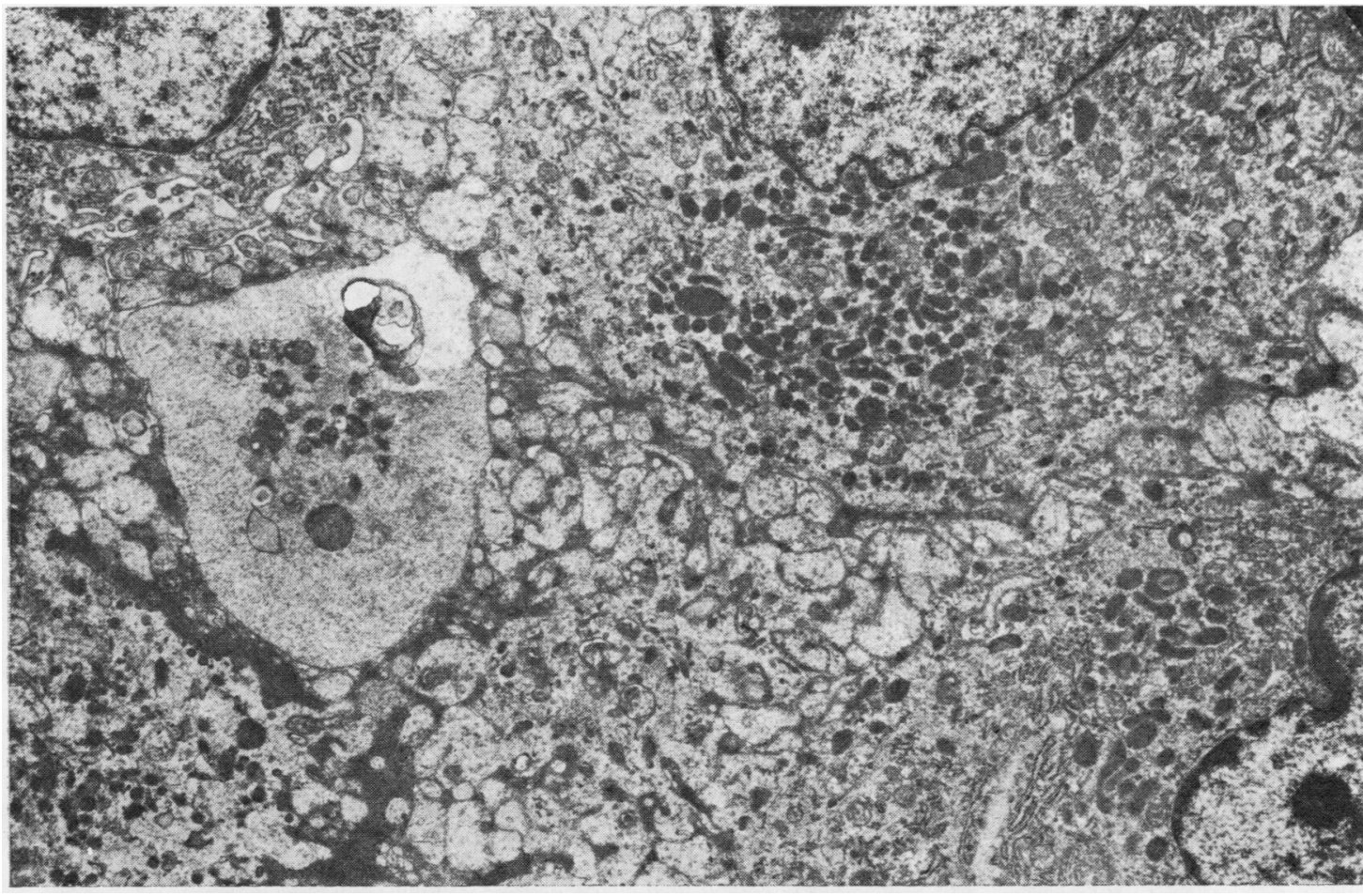

(1)

FIG. 6. Free alveolar cells rich in cytoplasmic dense bodies show complex interdigitation of their cell membranes but are devoid of junctional complexes. EM.L. and U. $\times 5,560$.

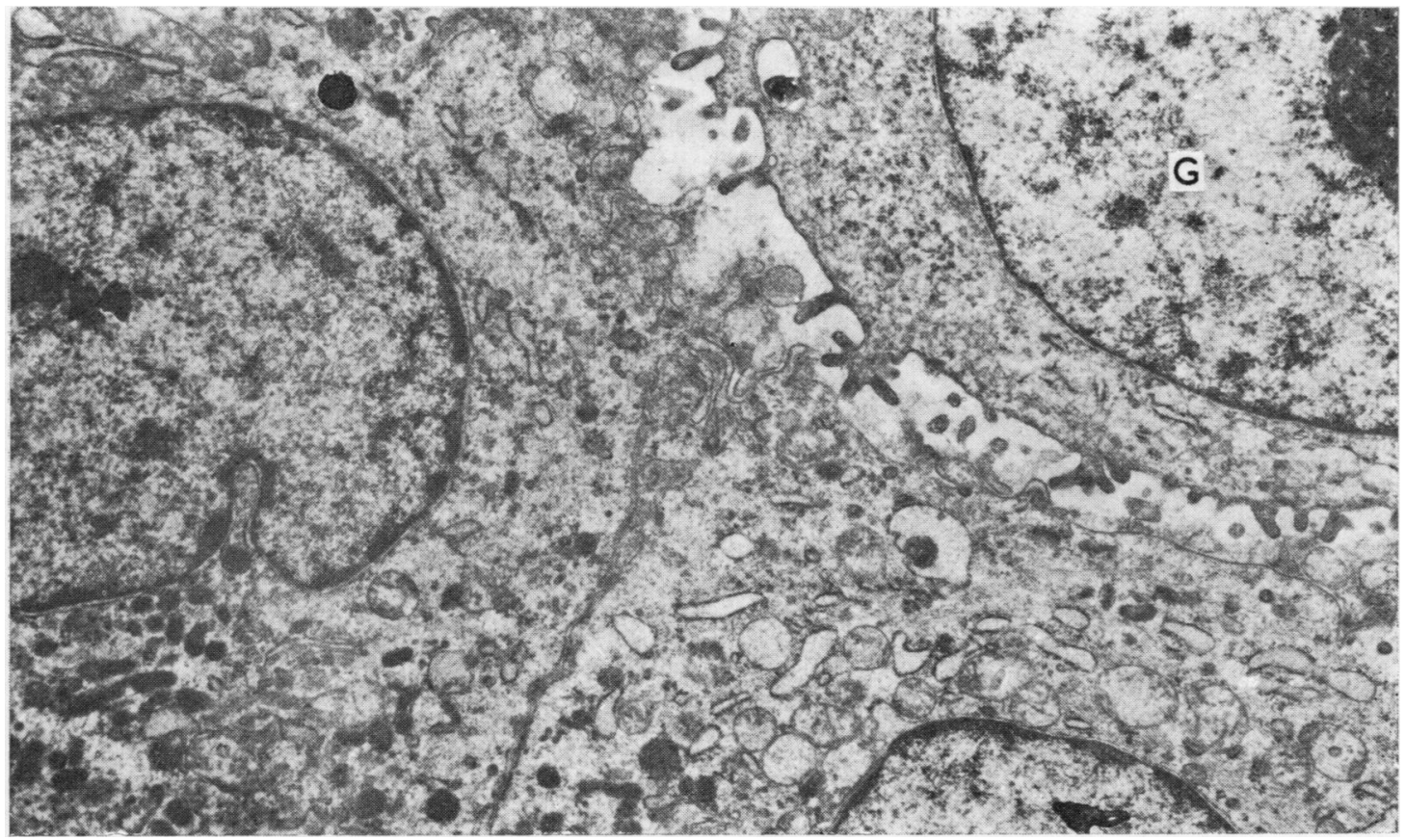

FiG. 7. Two macrophages rich in lysosomes and a granular pneumocyte $(G)$, which elsewhere adhered to the basement membrane. The surfaces of the macrophages are uneven and interdigitate but show no intercellular junctional complexes and lack the microvilli seen on the surface of the epithelial cell. EM.L. and U. $\times 9,200$. 


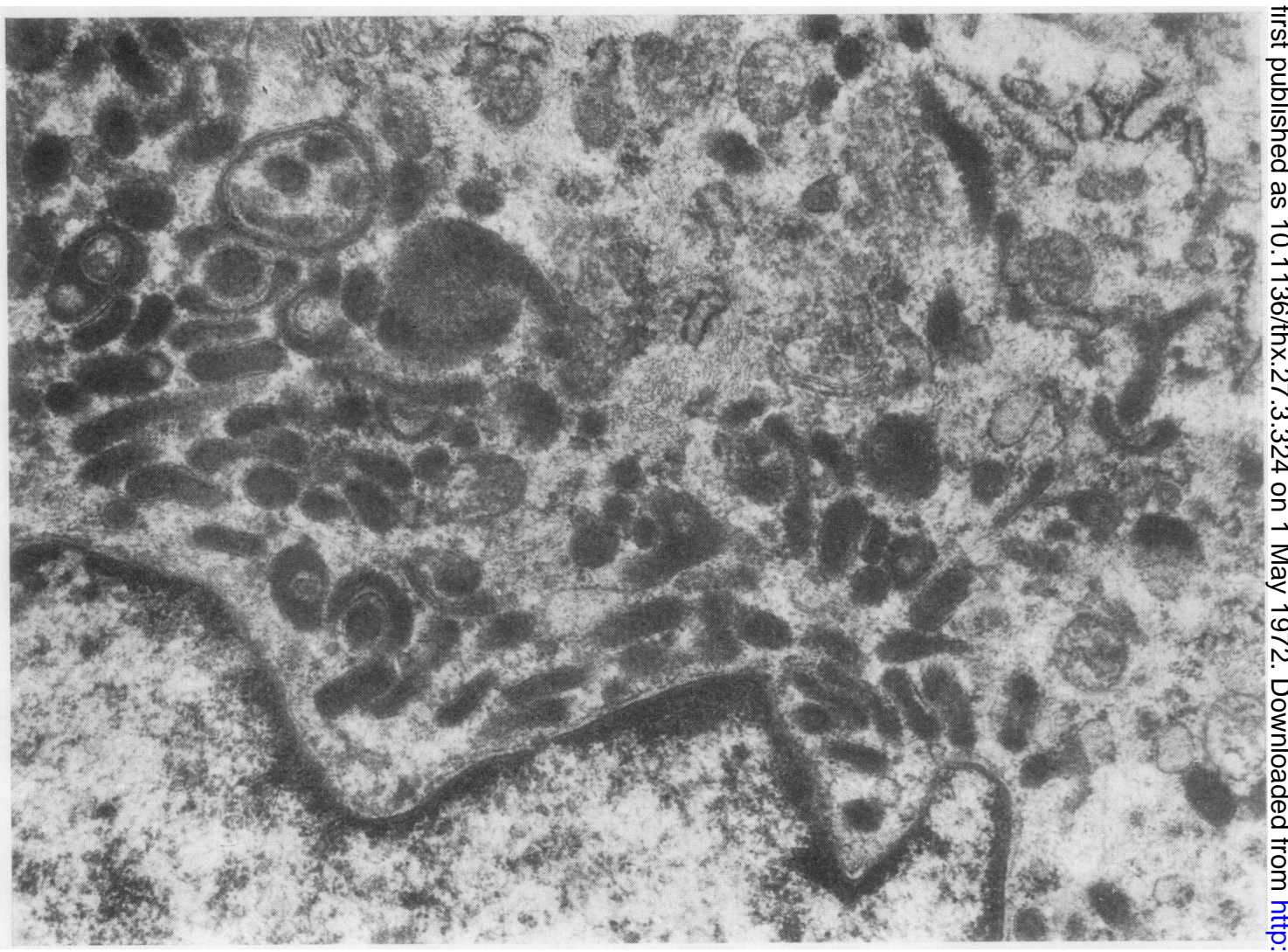

FIG. 8. Detail of a free alveolar cell showing many pleomorphic membrane-bound dense bodies. EM.L. and U. $\times 19,150$,

able viral or bacterial bodies. We agree with Patchefsky, Banner, and Freundlich (1971) that the viral-like inclusion bodies which have been reported in DIP are probably nucleolar structures (Fig. 5).

\section{DISCUSSION}

Except for the presence of asbestos bodies and free iron, the present case complies with previously published descriptions of DIP and was accepted as such by Professor A. A. Liebow. Electron microscopy shows quite clearly that in this patient the great majority, if not all, the free alveolar cells are macrophages bearing no resemblance to either type of alveolar epithelial cell. Our case, therefore, compares very well with that of Farr et al. (1970) but contrasts with that of Shortland et al. (1969). The cases of Brewer et al. (1969) and of Leroy (1969) occupy an intermediate position but, in having a predominance of macrophages, are nearer to the present case. A possible explanation for these varying reports is that the cellular 'desquamation $\frac{10}{3}$ is a phasic phenomenon involving first one cell type and then the other (Crane, 1971). Examination? of further cases will be required to test this hypo thesis, but here future workers should bear inf mind the danger of drawing false conclusions from the study of tangential sections. In the norma? lung, tangential sectioning of the type II pneumor cyte occasionally gives the impression that the celf is free in the alveolar space, neither its lateras cellular attachments nor its underlying basementw membrane being seen. All reports agree that the lining cells in DIP are type II pneumocytes and, aoo we have shown, these hyperplastic cells often proed trude far into the alveolar lumen while still retain ${ }^{+}$ ing attachments to adjacent epithelial cells. It is easy to imagine how tangential sectioning of such? cells could give the impression of many granulap pneumocytes free in the lumen. Experienced micro 8 scopists will avoid this pitfall but in cases of doubt serial sections will be required. An interesting point 
of interpretation is raised by Leroy, who makes careful note of persistent cell junctions between 'desquamated' granular pneumocytes and similar cells still attached to the epithelial basement membranes. In our view, such intact intercellular connexions indicate that these cells are not free in the alveolar space.

At present the nature of the free cells remains controversial but, of the six cases in which the fine structure is carefully described and well illustrated, macrophages preponderate in five (Table). Doubt

T A B L E

CASES OF DIP STUDIED IN DETAIL WITH THE ELECTRON

\begin{tabular}{l|l}
\multicolumn{1}{c}{ Reference } & \multicolumn{1}{c}{ Nature of Free Alveolar Cells } \\
\hline Shortland et al. (1969) & $\begin{array}{l}\text { Granular pneumocytes } \\
\text { with small numbers of macrophages }\end{array}$ \\
$\begin{array}{l}\text { Brewer et al. (1969) } \begin{array}{l}\text { Leroy (1969) case } 1 \\
\text { Leroy (1969) case } 2 \\
\text { Farr et al. (1970) }\end{array} \\
\text { Present study }\end{array}$ & $\begin{array}{l}\text { Mostly macrophages } \\
\text { with some granular pneumocytes }\end{array}$ \\
& $\begin{array}{l}90 \% \text { Macrophages } \\
\text { Macrophages }\end{array}$ \\
\hline
\end{tabular}

may therefore be expressed regarding the original view that the 'desquamated' cells are epithelial in origin. Recent animal studies may be relevant to this question. A DIP-like picture in rabbits given intravenous Freund's adjuvant and a similar condition induced in rats by oral iprindole have both been carefully studied by electron microscopy, histochemistry, and assessment of phagocytic ability. In both these conditions the free alveolar cells proved to be macrophages (Bhagwat and Conen, 1969; Vijeyaratnam and Corrin, 1972). Lastly, the production of DIP by such diverse stimuli as these, coupled with the finding of asbestos bodies in the present case, lead us to believe that DIP probably represents the result of various noxious influences rather than a specific disease entity. However, DIP presents a characteristic histological pattern, the clinical implications of which warrant its separate recognition.
We wish to thank Dr. R. D. Clay for permission to study this case and Mr. A. E. Clark and Mrs. M. Boniface for excellent technical assistance. We are also grateful to Professor H. Spencer for valuable advice.

\section{REFERENCES}

Bhagwat, A. G., and Conen, P. E. (1969). Characterization of 'free alveolar cells' in experimental adjuvant induced pneumonia. Arch. Path., 88, 21.

Brewer, D. B., Heath, D., and Asquith, P. (1969). Electron microscopy of desquamative interstitial pneumonia. J. Path., 97, 317.

Crane, W. A. J. (1971). Discussion at the 122nd meeting of the Pathological Society of Great Britain and Ireland.

Farr, G. H., Harley, R. A., and Hennigar, G. R. (1970). Desquamative interstitial pneumonia - an electron microscopic study. Amer. J. Path., 60, 347.

Goff, A. M., McNary, W. F. Jr., and Gaensler, E. A. (1967). Desquamative interstitial pneumonia. Med. thorac., 24, 317.

Karrer, H. E. (1958). The ultrastructure of mouse lung: the alveolar macrophage. J. biophys. biochem. Cytol., 4, 693.

- (1960). Electron microscopic study of the phagocytosis process in lung. J. biophys. biochem. Cytol., 7, 357.

Leroy, E. P. (1969). The blood-air barrier in desquamative interstitial pneumonia (D.I.P.). Virchows Arch. Abt. A. path. Anat., 348, 117.

Liebow, A. A., Steer, A., and Billingsley, J. G. (1965). Desquamative interstitial pneumonia. Amer. J. Med., 39, 369.

Meyrick, B., and Reid, L. (1970). The alveolar wall. Brit. J. Dis. Chest, 64, 121.

Patchefsky, A. S., Banner, M., and Freundlich, I. M. (1971). Desquamative interstitial pneumonia. Significance of intranuclear viral-like inclusion bodies. Ann. intern. Med., 74, 322.

Scadding, J. G., and Hinson, K. F. W. (1967). Diffuse fibrosing alveolitis (diffuse interstitial fibrosis of the lungs); correlation of histology at biopsy with prognosis. Thorax, 22, 291.

Shortland, J. R., Darke, C. S., and Crane, W. A. J. (1969). Electron microscopy of desquamative interstitial pneumonia. Thorax, 24, 192.

Sorokin, S. P. (1966). A morphologic and cytochemical study on the great alveolar cell. J. Histochem. Cytochem., $14,884$.

Vijeyaratnam, G. S., and Corrin, B. (1971). Experimental Paraquat poisoning: a histological and electron-optical study of the changes in the lung. J. Path., 103, 123.

(1972). Pulmonary histiocytosis simulating desquamative interstitial pneumonia in rats receiving oral iprindole. J. Path., in press. 